\title{
A IDEIA DE COOPERAÇÃO INTERINSTITUCIONAL PÚBLICA COMO ALAVANCA DO DESENVOLVIMENTO ECONÔMICO
}

\author{
THE IDEA OF PUBLIC INTERINSTITUTIONAL \\ COOPERATION AS A LEVER OF ECONOMIC DEVELOPMENT
}

\author{
VICTOR SALDANHA PRIEBE ${ }^{1}$
}

DANIEL DOTTES DE FREITAS ${ }^{2}$

\section{RESUMO}

Ao descrever a cooperação interinstitucional pública sob uma matriz teórica pragmática, busca-se, através de um estudo de caso, demonstrar a possibilidade de existência de um princípio constitucional implícito, o qual entende-se como um dos pilares de sustentação das políticas públicas tributárias destinadas aos entes federados. Diante dessa realidade, busca-se examinar a relação de cooperação interinstitucional que os entes federativos possuem, bem como vislumbrar a possibilidade de emancipação de tal princípio constitucional implícito em vias de proporcionar melhores resultados nas questões tributárias, e, consequentemente nas funções de Estado. Com o intuito de atender a essa finalidade, pretende-se responder as seguintes indagações: O princípio constitucional implícito da cooperação interinstitucional pública pode ser analisado sob uma matriz teórica pragmática? E, se positivo, é capaz de sustentar um modelo específico de política pública a ser implementada nos entes federados? Para exame do proposto, optou-se por um estudo de caso no qual utilizou-se na verificação dos dados uma análise de cunho interpretativo por meio da técnica de pesquisa bibliográfica. Concluiu-se, por conseguinte, que é plenamente possível o exame do tema à luz da matriz teórica pragmática, o que, permitiu compreender que a meta emancipatória do princípio da cooperação interinstitucional pública é absolutamente possível, de modo que pode de fato ser utilizado como base se sustentação para criação de políticas públicas tributárias voltadas aos entes federados.

PALAVRAS-CHAVE: Cooperação. Interinstitucional. Pública. Desenvolvimento. Econômico.

1 Mestre em Direito pelo Programa de Pós-Graduação Stricto Sensu da Universidade de Santa Cruz do Sul (PPGD-UNISC). Especialista em Direito Processual Cível pela Escola Paulista de Direito (EPD). Professor convidado na Pós-graduação Lato Sensu da Universidade de Santa Cruz do Sul (UNISC). Advogado. Cachoeira do Sul/RS. E-mail: victor.priebe@hotmail.com

2 Pós-Doutor em Direito pelo PNPD da Universidade Federal do Rio Grande do Sul (UFRGS), Doutor, Mestre e Especialista em Direito pelo PPGD da Universidade de Santa Cruz do Sul (UNISC). Professor da Faculdade Dom Alberto. Advogado. E-mail: danieldottes@ig.com.br. 


\section{ABSTRACT}

In describing public inter-institutional cooperation under a pragmatic theoretical framework, a case study is sought to demonstrate the possibility of an implicit constitutional principle, which is understood as one of the pillars of support for public tax policies aimed at to federated entities. In view of this reality, it is sought to examine the relationship of interinstitutional cooperation that federal entities possess, as well as to envisage the possibility of emancipation of such implicit constitutional principle in the way of providing better results in tax matters, and consequently in the functions of State. In order to meet this objective, the following questions are asked: Does the implicit constitutional principle of public inter-institutional cooperation be analyzed under a pragmatic theoretical framework? And, if positive, is it capable of sustaining a specific model of public policy to be implemented in the federated entities? In order to examine the proposal, we chose a case study in which an analysis of an interpretative character was used in the verification of the data by means of the bibliographic research technique. It was therefore concluded that it is entirely possible to examine the subject in the light of the theoretical pragmatic matrix, which has made it possible to understand that the emancipatory goal of the principle of public interinstitutional cooperation is absolutely possible, so that it can in fact be used as base if support for the creation of public tax policies directed to the federated entities.

KEYWORDS: Cooperation. Interinstitutional. Public. Development. Economic.

\section{INTRODUÇÃO}

Após descrever a hipótese daquilo que se denomina aqui de cooperação ${ }^{3}$ interinstitucional pública, construída a partir de um estudo de caso, o presente trabalho pretende observar tal possibilidade conforme os postulados da matriz teórica pragmática.

Com isso, propõe a construção de um recorte específico na forma de observação de um determinado fato do mundo, objetivando-se ao final uma modificação sobre o resultado do trabalho de pesquisa na lógica de observação, o que seria típico na compreensão e entendimento sobre a própria matriz teórica referida.

Noutra perspectiva, é um exercício praticado a bem de comprovar uma nova construção no pensamento dos autores, como questão de entendimento sobre o tema, quiçá, servível para influenciar os leitores. Assim, não pretende arvorar-se com especialidade e profundidade a ponto de esgotar o tema.

O trabalho apresentará um estudo de caso, a ser seguido por uma condição de possibilidade, onde a ideia de que este estudo permite vislumbrar a existência de um princípio constitucional implícito. Este, por seu turno, vem a sustentar um modelo específico de política pública a ser implementada entre os entes federados. Após tais construções, a ideia será submetida à lógica da matriz pragmática, com vistas à construção de uma emancipação possível do pensamento. 


\section{A COLOCAÇÃO DO PROBLEMA A PARTIR DE UM ESTUDO DE CASO}

No ano de 2006, por intermédio de uma atividade conjunta liderada pela administração pública municipal de Cruz Alta ${ }^{4}$, junto a bacia leiteira do noroeste do Estado do Rio Grande do Sul, foram realizadas diversas reuniões entre representes dos respectivos municípios e entre estes e a empresa "CCGL", a fim de implementarem uma política publica e um modelo de gestão que beneficiasse a todos os entes públicos interessados, no sentido de garantirem arrecadação fiscal decorrente da instalação da referida empresa naquela região, evitando entre eles a chamada guerra fiscal (disputa entre entes federados pela instalação de empresas).

A partir de tais reuniões, deliberou-se conjuntamente, que não haveria disputa entre os municípios quanto à instalação da empresa em seus territórios (fato que origina a chamada guerra fiscal dado o interesse comum de cada ente, com vistas à arrecadação tributária daí decorrente).

A guerra fiscal é uma situação fático-administrativa, que decorre do próprio caráter extrafiscal dos tributos. Sobre isso já afirmamos:

O princípio da extrafiscalidade em matéria tributária encontra-se diluído em diversos dispositivos constitucionais, mas também é encontrado na própria legislação infraconstitucional. Todavia, universalizando-se desse modo, permeia o conjunto normativo em todas as esferas da federação. Isto significa dizer que, por corolário lógico, é norma que se encontra em cada esfera da competência tributária estabelecida a partir da Constituição. [...] Mas a diretriz da extrafiscalidade é a busca do desenvolvimento social a partir, fundamentalmente, da intervenção nos domínios econômicos e sociais[...]. [...] Assim, além de não representar, obrigatoriamente, melhoria de vida às populações locais, especialmente quanto ao desenvolvimento humano, a atividade estatal institui a chamada guerra fiscal entre os entes da federação. Ela desenvolve no seio das administrações públicas a contumaz intenção de beneficiar tributariamente variadas empresas e indústrias, numa acirrada disputa local, regional e estadual, fazendo com que os entes federados, mutuamente, percam força, cedendo à exploração econômica patrocinada em favor apenas do capital privado (RODRIGUES, 2009, p. 2687-2692).

Para que fosse evitada a disputa pela instalação da empresa entre os municípios envolvidos, promoveu-se uma política pública solidária, harmoniosa e cooperada, seguida de um modelo de gestão compatível com a mesma, a fim de que todos se beneficiassem no âmbito tributário local e regional.

Acordou-se a elaboração de convênios entre o denominado município-sede e os demais municípios participantes (convenientes), para devolução dos aportes financeiros advindos da comercialização de leite (enviado pelos produtores de cada município), referentes ao chamado retorno de ICMS, o que se denomina de ICMS adicionado ao município-sede (Cruz

4 Cruz Alta situa-se no Rio Grande do Sul, Estado do extremo sul do Brasil, em uma região denominada Planalto Médio, com altitude média de 452 metros acima do nível do mar. Com clima ameno e povo hospitaleiro, Cruz Alta se constitui num dos pontos principais do mapa do Estado. Mais precisamente, o Município de Cruz Alta está situado no meio norte do Rio Grande do Sul, na micro-região 322, composta pelos municípios de: Cruz Alta, Ibirubá, Júlio de Castilhos, Santa Bárbara do Sul, Santiago, São Francisco de Assis, Tupanciretã e Fortaleza dos Valos." Disponível em: http://www.culturagaucha.com. br. Acesso em: 15 de maio de 2020. 
Alta), e que seria devolvido a cada um dos participantes como retorno de tributação proporcional ao que enviaram à empresa instalada em Cruz Alta.

Formalizados os convênios a partir de uma lei municipal de Cruz Alta, que reconhecia tal possibilidade, a empresa participante se responsabilizou por informar ao município-sede os quantitativos de produtos enviados pelos demais, permitindo-se a repartição proporcional da tributação e sua devolução a cada um deles.

Sob estudo, este caso permite várias avaliações e conclusões, das quais emerge a proposta de reconhecimento de um modelo de cooperação pública entre entes federados, que transcende os conceitos de solidariedade e harmonização em sede de políticas públicas.

Ao contrário dos demais conceitos, a cooperação ${ }^{5}$ incorpora uma atitude, ou seja, determina uma efetiva atuação para que duas ou mais pessoas executem uma conduta antes aceita por todas. Mas este tema terá tratamento específico no próximo item.

Especialmente quanto ao exemplo aqui tratado como estudo de caso e, mais adequadamente, como estudo de caso piloto, verifica-se que no ambiente da triagem sua seleção é adequada por incorporar diversas características servíveis à investigação.

Nas palavras de Robert K. Yin, a utilização do caso piloto assumiu o papel de "laboratório" para a pesquisa, cumprindo seu desiderato:

O local usado pelo caso-piloto poderia, por conseguinte, assumir o papel de um "laboratório" para os pesquisadores, permitindo-Ihes observar fenômenos diferentes de muitos ângulos diferentes e testar abordagens diferentes em uma base experimental (YIN, 2005, p. 104).

Para fins metodológicos o caso acima descrito forneceu os elementos indispensáveis à comprovação das ocorrências acima descritas.

O pesquisador visitou a administração pública de Cruz Alta, no Rio Grande do Sul, tendo acesso a todos os elementos acima descritos, como atas de reunião, legislação, setores responsáveis pela execução de atividades e demais informações comprobatórias daquela atuação administrativa.

Assim, serve o presente para configurar a confirmação do caso, nos termos em que foi investigado. O caso de Cruz Alta cumpriu o papel de representação do modelo de cooperação interinstitucional pública, ou seja, demonstrou a aplicação prática de um modelo de cooperação entre entes federados municipais, servindo aos propósitos de verificação das circunstâncias teórico-científicas que podem sustentar o próprio modelo.

Mas do ponto de vista científico, o que seria isso? No contexto da matriz pragmática, o que representaria a cooperação nos moldes aqui apresentados? Pretende-se responder estas duas questões nos itens subsequentes. 


\section{O SURGIMENTO DA IDEIA DE COOPERAÇÃO INTERINSTITUCIONAL PÚBLICA}

A partir do estudo de caso acima veiculado de forma resumida, verificou-se uma ocorrência prática, a cooperação entre os municípios a fim de que todos aqueles pertencentes à bacia leiteira da região noroeste do Estado do Rio Grande do Sul, se beneficiassem com a devolução do ICMS adicionado ao município-sede, ou seja, recebendo de forma proporcional o tributo referente ao produto saído de seu território.

Este caso cumpre a função de base experimental para uma avaliação científica, qual seja, a de visualizar as atitudes administrativas que foram adotadas, como uma espécie de cooperação havida no âmbito da administração pública municipal, entre os municípios, cuja finalidade foi a de atingir interesses regionais, comuns, em detrimento da habitual disputa existente entre eles, e que poderia ser repetida à despeito do que ocorre em todo o país.

Naquele momento os municípios envolvidos relegaram a tradicional disputa pela instalação da empresa em seu território, promovendo uma estratégia comum que beneficiasse cada um deles e, bem assim, toda a região. Do ponto de vista pragmático lançaram mão de uma técnica capaz de incorporar seus verdadeiros anseios.

Mas se seus anseios embasaram-se no bem comum regional, há que se reconhecer a existência de outros fundamentos dando suporte a esta conduta, a esta técnica de atuação prática (cooperação), quais sejam: primeiro, rememorando fundamentos morais universais, como por exemplo, a proteção e o desenvolvimento da vida humana; segundo, assumindo uma conduta ética correspondente a tais anseios, relegando traições e egoísmos, assumindo a vontade da comunidade, o próprio bem comum.

Já assumindo a linguagem habermasiana, há que se afirmar que a ideia de cooperação interinstitucional pública incorpora os três tipos de argumentos para a deliberação pública, conformando-se com a matriz pragmática da comunicação, de Jürgen Habermas.

Todavia, por questões metodológicas, neste momento cabe afirmar apenas que o exercício científico que será feito a seguir, utilizará a matriz habermasiana para demonstrar que a prática cooperada examinada, leva à ideia de que existe um princípio da cooperação interinstitucional pública, ou seja, especial, entre entes federados, e que tal princípio sustenta um modelo de política e gestão públicas.

Importa referir uma preocupação de fundo no sentido de questionar se a juridicização do princípio da cooperação interinstitucional pública e a criação de um modelo dessa natureza seriam determinantes para uma conduta pública nestes termos. Na verdade, não! Mas a decisão de juridicizar, sim!

Ora, a seguir será demonstrado que isso é possível, todavia, se antes estiverem presentes os postulados habermasianos acima referidos e que residem no tenso ambiente situado entre faticidade e validade, como alude Habermas:

Qualquer sociologia desejosa de ter acesso ao seu campo de objetos, passando pela compreensão hermenêutica do sentido, tem que levar em conta essa tensão entre facticidade e validade.[...] Os participantes da interação têm que atribuir-se reciprocamente a consciência de seus atos, ou seja, têm 
que supor que eles são capazes de orientar seu agir por pretensões de validade (HABERMAS, 1987, p. 38).

Noutras palavras, numa primeira leitura do problema, pode-se afirmar que não haverá cooperação interinstitucional pública, nem tampouco qualquer modelo dela emergente, mesmo que juridicizado, sem que no caminho percorrido entre o fato e a validade da norma na consciência humana, todos aqueles argumentos para deliberação e decisão pública estejam presentes. Esta seria a leitura pragmática do caso em estudo.

\section{O CASO EM ESTUDO À LUZ DA TEORIA DA AÇÁO COMUNICATIVA: UMA DEMONSTRAÇÃO POSSÍVEL E ACEITÁVEL}

Uma preocupação fundamental no pensamento de Habermas que pode servir como ponto de partida para este estudo, consiste em sua preocupação com o processo de emancipação do ser humano. Da metafísica à racionalidade transcendente salta evidente a preocupação em desvendar o conhecimento humano sobre o mundo e a fixação das bases que orientam (se não, determinam) seu pensamento.

Nesse contexto a teoria da ação comunicativa responsabiliza-se por uma espécie de virada paradigmática da intersubjetividade. Do contexto de suas obras, Habermas constrói os conceitos de razão, verdade, democracia e direito, na intersubjetividade discursiva. A comunicação é, então, o fator determinante das decisões humanas.

E como a decisão haurida a partir da comunicação forma e conforma a cooperação interinstitucional pública?

Para responder-se esta principal questão, é necessário um desdobramento. Primeiro, fixando a ação comunicativa como o berço para a descoberta da verdade na relação havida entre sujeito cognoscente e objeto cognoscível, situação que fixa um ponto de partida para aquilo que se chama decisão, mais precisamente direito enquanto decisão. Depois, alocando a ideia de cooperação interinstitucional pública no ambiente da própria matriz pragmática, para demonstrar o que realmente lhe origina e o que pode determinar sua utilização de forma mais universalizada.

Nesse contexto seria demonstrada a emancipação teórica referida no título do trabaIho. Seria o reconhecimento de que a cooperação interinstitucional pública enquanto princípio jurídico constitucional implícito e enquanto modelo a ser utilizado noutros casos, não se sustenta na normatividade do direito (para geração de obediência), ou seja, na suposta essência do direito; mas que se sustenta na decisão comunicativa que o antecede. E a razão comunicativa suporta os argumentos para a deliberação pública.

Em realidade, sustenta os fundamentos ético, moral e pragmático, retirando do direito (normativo) um conteúdo que pretensamente seria seu. Estar-se-ia, ainda, diante dos denominados déficits que prejudicam o trânsito para uma nova racionalidade (a racionalidade comunicativa). 
Na teoria de la acción comunicativa i, racionalidad de la acción y racionalización social, Habermas inicia a incursão da razão comunicativa como fundamento básico para a ação comunicativa. Veja-se:

Podemos decidir, en resumen, que las acciones reguladas por normas, las autopresentaciones expresivas y las manifestaciones o emisiones evaluativas vienen a completar los actos de habla constatativos para configurar una práctica comunicativa que sobre el trasfondo de un mundo de la vida tiende a la consecución, mantenimiento y renovación de un consenso que descansa sobre el reconocimiento intersubjetivo de pretensiones de validez susceptibles de crítica. La racionalidad inmanente a esta práctica se pone de manifiesto en que el acuerdo alcanzado comunicativamente ha de apoyarse en última instancia en razones $\mathrm{Y}$ la racionalidad de aquellos que participan en esta práctica comunicativa se mide por su capacidad de fundamentar sus manifestaciones o emisiones en las circunstancias apropiadas La racionalidad inmanente a la práctica comunicativa cotidiana remite, pues, a la práctica de la argumentación como instancia de apelación que permite proseguir la acción comunicativa con otros medios cuando se produce un desacuerdo que ya no puede ser absorbido por las rutinas cotidianas y que, sin embargo, tampoco puede ser decidido por el empleo directo, o por el uso estratégico, del poder.

Por eso pienso que el concepto de racionalidad comunicativa, que hace referida a una conexión sistemática, hasta hoy todavía no aclarada, de pretensiones universales de validez, tiene que ser adecuadamente desarrollado por medio de una teoría de la argumentación (HABERMAS, 1987, p. 36).

Ele afirma que as ações reguladas por normas vêm completar os atos de fala, configurando uma prática comunicativa sobre tudo o que se vê sobre o mundo, a própria representação que cada pessoa humana tem sobre o mundo, bem como aquilo que um grupo (por exemplo), assume e comunica como tal. Daí emerge o que denomina de racionalidade comunicativa.

Trata-se da construção de uma matriz no âmbito da fenomenologia do conhecimento que soluciona o problema da gnosiologia. Aquilo que o objeto é, o é por obra da comunicação, mais precisamente das escolhas comunicativas das pessoas. Assim, trata-se de decisão em âmbito comunicativo. Por isso, a afirmação de que direito é decisão.

E aquele caso piloto acima veiculado guardaria esta mesma situação? Adiante isso será demonstrado. As afirmações de Habermas sobre a interpretação dos fatos da vida segundo o modelo da ação comunicativa:

En el caso de la acción comunicativa los rendimientos interpretativos de que se construyen los procesos cooperativos de interpretación representan el mecanismo de cooperativos de la acción; la acción comunicativa no se agota en el acto de entendimiento efectuado en términos de interpretación. Si escogemos como unidad de análisis un acto de habla sencillo realizado por $H$, frente al que por lo menos otro participante en la interacción puede tomar postura con un $<<$ sí > > o con un $<<n o>>$, podremos clarificar las condiciones de la coordinación comunicativa de la acción indicando qué quiere decir que un oyente entienda el significado de lo dicho 164. Pero la acción comunicativa designa un tipo de interacciones que vienen coordinadas mediante actos de habla, mas que no coinciden con ellos (HABERMAS, 1987, p. 136). 
Verifica-se aqui, que Habermas transporta o ato de comunicação entre o sujeito cognoscente e o objeto cognoscível para o ambiente coletivo, ocasião em que outro ou outros membros podem tomar postura sobre aquela comunicação, aceitando ou não, modificando-a ou não, surgindo assim a ideia de concordância comunicativa decorrente da ação. Ora, isso seria a própria significação do objeto.

Ele segue seu raciocínio no ambiente linguístico em que constrói a teoria da ação comunicativa. Trata-se da construção linguística de uma realidade fictícia.

El deslinde lingüístico entre los planos de realidad que representan el <<juego>> y el <<ir en serio>>, la construcción lingüística de una realidad ficticia, el chiste y la ironía, el uso translaticio y paradójico del lenguaje, las alusiones, las revocaciones contradictorias de pretensiones de validez en el plano metalingüístico- todo ello se basa en una confusión intencionada de modalidades del ser. La pragmática formal puede aportar a la aclaración de los mecanismos que el hablante necesita para dominar todo ello, mucho más que lo que puede aportar una simples descripción empírica, por exacta que sea, de los fenómenos a explicar. El niño, al irse ejercitando en los modos fundamentales del uso del lenguaje, adquiere la capacidad de trazar los límites entre la subjetividad de sus propias vivencias, la objetividad de la realidad objetualizada, la normatividad de la sociedad y la inter-subjetividad de la comunicación lingüística. Al aprender a tratar hipotéticamente las correspondientes pretensiones de validez, se ejercita en las distinciones categoriales entre esencia y fenómeno, ser y apariencia, ser y deber, signo y significado. $Y$ junto a estas modalidades entitativas, se hace también con la posibilidad de manipular esos fenómenos de engaño que inicialmente se deben a una confusión involuntaria entre la propia subjetividad, de un lado, y los ámbitos de lo objetivo, lo normativo y lo intersubjetivo, de otro. Ahora sabe cómo dominar las confusiones y cómo generar de propósito desdiferenciaciones que puede utilizar en la ficción, en el chiste, en la ironía, etc (HABERMAS, 1987, p. 424-425).

Não obstante a grandeza da obra e, na mesma proporção, a densidade do texto habermasiano, pode-se utilizar a passagem acima como exemplo do grande giro hermenêutico que Habermas faz ao examinar o problema do conhecimento. Ao afirmar que em âmbito lingüístico, o homem constrói uma realidade fictícia sobre uma realidade real (permitida a redundância) a qual não se tem acesso, o autor promove o modelo de ação comunicativa como sustentáculo das bases do conhecimento sobre as coisas do mundo. 0 que sabemos sobre a realidade é produto da interação comunicativa. Estabelecida a comunicação entre o sujeito e o objeto, haverá que decidir a representação sobre o objeto. Esse seria o caminho entre fato e validade. 0 objeto encontra uma condição de validez, após construído o fato no complexo ambiente da percepção humana.

É possível afirmar-se, então, que a teoria da ação comunicativa implica uma concepção comunicativa acerca do próprio conhecimento. Tal trabalho é feito no caso escolhido aqui, a cooperação interinstitucional pública.

Não há espaço aqui para outras digressões sobre moralidade (por exemplo), como fator a influenciar o pensamento do sujeito. Apenas se pretende referir o sentido do conhecimento sobre o objeto segundo a teoria da ação comunicativa. E daí aplicá-lo no caso em estudo já na imbricação pragmática. 
O caso em estudo parece conter uma circunstância absolutamente peculiar, suficiente para demonstrar com absoluta clareza, não apenas a ideia de ação comunicativa nele havida, mas o surgimento de um novo pensar sobre o seu objeto, diferentemente do que antes vinha ocorrendo. E tal atitude representará uma emancipação no modo de se exercitar a política tributária e a competência municipal.

\section{A IDEIA DE COOPERAÇÁO INTERINSTITUCIONAL PÚBLICA CONFORME A OBSERVAÇÁO TEÓRICA PRAGMÁTICA: UMA EMANCIPAÇÃO POSSÍVEL}

Depois de sustentadas as hipóteses de trabalho e os conceitos que orientam a questão de fundo deste trabalho, é o momento de examinar o que se denomina de ideia de cooperação interinstitucional pública, mediante a aplicação da matriz pragmática. Trata-se de examinar o problema da decisão política e jurídica que deu sentido ao caso em estudo, ou seja, aplicação da matriz pragmática na observação desta situação em especial, com vistas ao reconhecimento de um ato-fato administrativo quase paradigmático, que ultrapassou os padrões comuns da atuação pública.

Perguntar-se-ia, assim, como a matriz pragmática observa essa atuação em nível de competência municipal, em que a tradicional guerra fiscal seria a pedra-de-toque da relação havida entre os municípios participantes do convênio?

Preliminarmente, é importante justificar o presente exame segundo tal opção teórica. A escolha representa um desafio dada a complexidade da teoria pragmática.

Conforme afirma Janriê Rodrigues Reck, ao examinar a filosofia da linguagem, não existe pensamento desconectado da linguagem. Não há conteúdo para uma norma, senão um pacto semântico assentado em definições humanas comuns, sobre as coisas.

Percebe-se que a produção do conhecimento (e a produção do Direito) é um processo complexo que envolve a interação de pessoas entre si e com a sua cultura, através da linguagem. Esta passa a ser o conceito chave, uma vez que mais do que mediação é também condição de possibilidade de qualquer vivência e de acesso ao mundo. As matrizes teóricas mais usadas já estão em conformidade com este paradigma filosófico (RECK, [S.I.: s.n], a).

Dada tal circunstância de análise científica, haverá a formação de um juízo sobre o objeto, e a consciência deste fato muda a própria racionalidade desenvolvida. Muda, pois, o acesso ao mundo. A matriz aqui escolhida é uma linguagem escolhida para observar o caso relatado no início, para verificar se existem questões de fundo importantes e que sirvam de referência na prática jurídica e política.

A matriz pragmática ajudará a compreender o fenômeno ocorrido em Cruz Alta, não apenas desvendando a decisão administrativa política e jurídica tomadas, mas relevando que nela reside o conhecimento e a opção humana sobre o ato-fato praticado naquela comunidade, e que destoa dos tradicionalmente adotados. 
Mas, evidentemente, não se pretende identificar o "melhor conhecimento possível", mas demonstrar uma possibilidade e sua razoabilidade, como um verdadeiro exercício teórico. Por certo, se admitida a adequação desta proposta científica, haverá de - em certo grau - diminuir a angústia decorrente da coerção, como refere Reck. E como diz o autor, é a qualidade do argumento utilizado que evita o aprisionamento e constrói a emancipação da pessoa pelo conhecimento sobre o objeto.

Por isso a afirmação de que a escolha da matriz teórica está diretamente relacionada com a emancipação do indivíduo. Quanto melhor a matriz, maior será a emancipação, porque mais livrará das coerções.

Na hipótese deste artigo científico a questão da união de diversos municípios de uma determinada região do Rio Grande do Sul, para superação de um problema habitual e costumeiro, surge como uma oportunidade para a construção do conhecimento.

Ao aplicar o modelo pragmático-sistêmico, Reck ensina que uma comunicação torna-se jurídica ao se enlaçar com os símbolos do sistema, o que corresponde a ser capaz de igualdade e validade:

Uma comunicação torna-se jurídica ao se enlaçar com os símbolos do sistema, isto é, deve ser capaz de igualdade e validade. Mesmo que, para Luhmann, os símbolos não tenham conteúdo, sendo meramente representação do movimento do sistema, o enlace gera um pouco mais de precisão ao exigir produção de novas operações de redundância (isto é, justificação de por que a comunicação observada pelo Direito pode se manter jurídica). A comunicação tem de ser capaz de se enlaçar com a ideia de que ela valeria para uma generalidade de casos e com a ideia de que ela estaria conforme $o$ todo do sistema. (RECK, [S.I.: s.n.], b)

Como explica ele, o enlace de símbolos (como é o caso das letras jurídicas) produz novas operações de redundância, equivalentes à replicação do conhecimento jurídico que se tem sobre determinado dispositivo legal, por exemplo. Então um artigo de lei é para mim, como é para muitos outros, devido a esta reprodução em que a comunicação se instalou, mas tudo em razão de que decidimos que fosse assim.

Foi exatamente esse exercício que aconteceu em Cruz Alta no trato da questão referente à devolução do ICMS adicionado, advindo dos municípios pertencentes à bacia leiteira. Ao invés de promoverem entre si a guerra fiscal, disputando a empresa "CCGL", mediante o oferecimento de vantagens a ela em detrimento do próprio município e dos demais relacionados, optou-se por uma atuação a partir de um novo nível de moralidade.

Nada obrigava a atitude tomada na região noroeste do Rio Grande do Sul. Ao contrário, as normas que regem a matéria sobre a competência municipal (principalmente a constitucional) não impedem que um município negocie a vinda diretamente com empresa; sua instalação e a concessão de benefícios fiscais com vistas ao futuro desenvolvimento local, principalmente com aportes financeiros decorrentes do ICMS adicionado, são situações absolutamente usuais.

É de se pensar que cada prefeito municipal tem a obrigação de proteger o desenvolvimento de seu município, sua comunidade, sem qualquer obrigação ou mesmo preocupação com os demais municípios. Seria responsável pela defesa de um interesse público condensado pelos limites da base territorial de cada ente municipal. 
Mas não foi isso o que aconteceu naquela localidade. Uma comunicação foi estabelecida entre as lideranças locais, emergindo uma decisão de âmbito político-jurídico, capitaneada por um novo padrão de moralidade, mais elevado, e que amplia o senso de bem comum.

Voltando-se para a pergunta principal sobre a aplicação da pragmática da comunicação, a ação comunicativa (fundada nos ditames processuais da razão comunicativa) formou e conformou a cooperação pública entre os municípios. Como demonstrado por Habermas, efetivou-se a escolha por uma norma melhor para todos, dada a maturidade dos intérpretes. Seu estágio de desenvolvimento moral permitiu um agir comunicativo a partir de um novo padrão, e que teve ressonância em âmbito regional, pois se tem notícia que todos os municípios interessados abandonaram a ideia de disputa (com os mecanismos oferecidos pela fiscalidade tributária), para se somar a uma proposta coletiva.

No caso específico de Cruz Alta, o esforço seria ainda menor, caso optasse pela guerra fiscal. É o maior município da localidade, sendo certo que venceria a disputa dadas as possibilidades e a preferência já existentes. Conforme a linguagem habermasiana, percorreu-se o caminho entre "a coerção fática e a validade legítima". (HABERMAS, 2003, p. 47)

Há bastante segurança no reconhecimento desse caso enquanto exemplo próprio à pragmática da comunicação. Trata-se de uma visão aceitável, pois ocorreu que a validade social da norma de direito municipal que regulamentou os convênios, foi determinada pelo grau de imposição, ou seja, aceitação fática no círculo de prefeitos municipais da região da bacia leiteira de Cruz Alta.

A validade social de normas do direito é determinada pelo grau em que consegue se impor, ou seja, pela sua possível aceitação fática no círculo dos membros do direito. Ao contrário da validade convencional dos usos e costumes, o direito normatizado não se apóia sobre a facticidade de formas de vida consuetudinárias e tradicionais, e sim sobre a facticidade artificial da ameaça de sanções definidas conforme o direito e que podem ser impostas pelo tribunal. (HABERMAS, 2003, p. 50)

É o reconhecimento de que o conceito 'mundo da vida' da teoria da comunicação, também rompe com o modelo de uma totalidade que se compõe de partes, concluindo Habermas que o mundo da vida configura-se como uma rede ramificada de ações comunicativas que se difundem em espaços sociais e épocas históricas foi o que ocorreu no caso em estudo, quando a ação comunicativa se alimentou das fontes culturais, ordenação legítima e identidade dos indivíduos socializados que participaram deste processo, cuja característica mais marcante deixada é a de que experimentaram uma verdadeira emancipação. A mesma emancipação de que se regozija o autor deste trabalho ao afirmar a pertinência da matriz teórica pragmática a partir deste estudo de caso (HABERMAS, 2003, p. 50-52).

Assim, resta adiantada a principal conclusão buscada neste trabalho, qual seja, a de que a ocorrência fática - enquanto exemplo simplificado de caso - incorpora os três tipos de argumentos levados para a deliberação pública: ético, moral e pragmático.

O fato relatado demonstra que foi retomado o conteúdo ético mais adequado para representar o bem comum. Expandiu-se a definição jurídica que reduz o bem comum à defesa dos interesses comunitários locais, para um modelo de defesa regional e a partir da cooperação. 
Nesse caminho a referência moral (proposições universais) sustentou a consciência de que o modelo usual estava e está errado ou distorcido, maculando o bem comum na sua concepção mais original, incorporadora daquilo que se denomina universalidade.

Assim, a pragmática da comunicação se insere neste contexto como uma técnica possível para resolução de conflitos. No estudo do caso Cruz Alta \& "CCGL" foi feito o caminho inverso, demonstrando que todo seu itinerário incorpora as definições pragmáticas, fundamentando a política pública cooperativa.

Em linhas finais ainda é necessário demonstrar o mínimo de entendimento da matriz aqui utilizada, sob pena não haver compreensão sobre seus enlaces e desenlaces, não obstante a utilização, tão só, de alguns de seus preceitos fundamentais. Isso é necessário, porque "se a matriz teórica foi compreendida, ela modifica o resultado do trabalho", como explica Reck ([S.I.: s.n.], a).

No presente estudo de caso a matriz foi satisfatoriamente aplicada, tendo sido vivenciada quando do entendimento de que seus postulados fundamentais foram descortinados no caso de Cruz Alta. Não se limitou a um modo de apresentação de trabalho, senão como fundamento para a emancipação teórica. Efetivamente a pragmática da comunicação ajudou a compreender o fenômeno ocorrido naquela região do Rio Grande do Sul, especialmente quando os acontecimentos lá praticados foram revolvidos à luz dos postulados teóricos da matriz. Significa dizer que as reuniões, deliberações, decisões e atitudes que efetivaram a cooperação pública institucional naquele ambiente de políticas públicas tributárias amparam-se nos postulados da pragmática comunicativa.

Com Reck, o conceito específico sobre a matriz aqui eleita, a fim de que se evidencie mais a correção da incursão realizada:

Esta matriz tem este nome por que, dentre as dimensões de análise possível
da linguagem, concentram seus estudos dentro do campo pragmático, isto
é, no que a linguagem pode servir enquanto instrumento de entendimento,
ou de como a intenção funciona na formação do significado (lembrando que,
para Habermas, o significado se forma a partir de um consenso onde atuam
intenção do falante, hermenêutica do ouvinte e cumprimento dos jogos de
linguagem) (RECK, [S.I.: s.n.], c).

A base da matriz está na linguagem enquanto instrumento para o conhecimento sobre as coisas do mundo. A pertinência disso parece decorrer do eterno problema apresentado pela filosofia clássica, de que o acesso ao objeto, ou seja, as coisas do mundo, não ocorre como realmente parece ocorrer. A relação entre sujeito e objeto se traduz num exercício mental em que o cognoscente constrói e reconstrói o objeto de observação (as coisas do mundo).

Retomando aspectos relevantes da matriz e aplicando-os no caso sob estudo, tem-se que - por inexistir pensamento desconectado da linguagem - aquele grupo de pessoas que gerenciavam o interesse público local e regional, fixaram um novo pacto semântico (novas definições), para refazer a realidade problemática.

O tema da competência tributária local, no que se refere à outorga de isenções, benefícios fiscais ou outras atividades atrativas do meio empresarial, sofreu uma releitura determinante de um novo modo de agir que pode sustentar o reconhecimento de um princípio de nível jurídico que, por sua vez, pode sustentar um novo e interessante modelo de atuação administrativa entre os entes federados. É o modelo cooperativo interinstitucional público. 
Ora, parece evidente que a matriz teórica eleita neste trabalho atinge satisfatoriamente a pretensão de emancipação, mais especialmente ao permitir uma universalização do conhecimento sobre este fato humano.

Noutras palavras, ela permeia de forma bastante clara todos os fundamentos do estudo de caso, perpassando todos os atos desenvolvidos por aqueles agentes públicos responsáveis por aquela nova prática administrativa, o que se vê como fundamentação racional que pode sustentar o modelo cooperativo no formato aqui reverenciado.

Há uma relação de trocas "a fim de fundamentar os princípios para uma organização política do poder público sob pontos de vista da teoria do discurso", como ensina Habermas (2003, p. 211).

A natureza extrafiscal dos tributos permite a guerra fiscal entre entes da federação. Não obstante a disputa ter atingido as raias do costume administrativo, na região de Cruz Alta, no Rio Grande do Sul, os líderes políticos dos municípios envolvidos promoveram o exame de normas controversas de normas controversas, mediante o princípio da universalidade, que permite encontrar um benefício que atinja um número maior de pessoas. Trata de regular a convivência no interesse simétrico de todos, nas palavras do supracitado autor:

Em questões morais, o ponto de vista teleológico, que nos permite enfrentar problemas por meio de uma cooperação voltada a um fim, desaparece por trás do ponto de vista normativo, sob o qual nós examinamos a possibilidade de regular nossa convivência no interesse simétrico de todos. [...] 0 princípio da universalização obriga os participantes do discurso a examinar normas controversas, servindo-se de casos particulares previsivelmente típicos, para descobrir se elas poderiam encontrar o assentimento refletido de todos os atingidos (HABERMAS, 2003, p. 203).

Veja-se a evidência da referência atos de comunicação, na exata medida em que o direito de antes do caso (regras de tributação ou competência municipal e tributária) não sofreu alteração, nem mesmo mitigação. 0 padrão comunicativo embasado na universalidade proposta para beneficiar o maior número possível de pessoas, foi determinante como modelo pragmático para emancipação no trato da questão.

\section{CONCLUSÃO}

Em sede conclusiva é pertinente registrar que a proposição atingiu seus objetivos. Foi possível aplicar à saciedade a matriz pragmática ao caso sob estudo, dadas as idiossincrasias que o cercavam permitindo uma completa submissão aos principais postulados da matriz.

Assim, serve o presente como comprovação de que é absolutamente possível o exame do tema da cooperação interinstitucional pública a partir de tal teoria, o que permite e demanda aprofundamento futuros, em prol de sua defesa.

A concepção científica pragmática permitiu compreender o fenômeno examinado como estudo de caso, de forma a fixar com máxima clareza os próprios limites perseguidos pela fenomenologia do conhecimento, permitindo o reexame de diversos institutos produzidos 
pelo homem, como linguagem, política e direito, ocasião em que suas realidades, posições e possibilidades restaram sobejamente fixadas, cumprindo-se a meta emancipatória pretendida.

\section{REFERÊNCIAS}

BÜTTENBENDER, Pedro Luís. O cooperativismo e o desenvolvimento regional: Estudo sobre as contribuições das cooperativas e das associações no desenvolvimento da região da Grande Santa Rosa. Unisinos. Revista Perspectiva Econômica - Série Cooperativismo nº 36 - Vol. 29 - nº 86 - julho/setembro. São Leopoldo: Unisinos, 1994.

HABERMAS, Jürgen. Direito e Democracia, entre facticidade e validade I. $2^{\mathrm{a}}$ ed. Tradução de Flávio Beno Siebeneichler. Rio de Janeiro: Tempo Brasileiro, 2003.

HABERMAS, Jürgen. Teoria de la acción comunicativa I, Racionalidad de la y racionalización social. Tradução para o espanhol, de REDONDO, Manuel Jiménez. Madrid: Taurus, 1987.

RECK, Janriê Rodrigues. Ciência, Direito e Educação: o debate acerca das matrizes teóricas, áreas de concentração e linhas pesquisa. [S.I.: s. n.] (a).

RECK, Janriê Rodrigues. Observação pragmático-sistêmica da competência enquanto decisão coordenadora de ações. [S.I.: s. n.] (b)

RECK, Janriê Rodrigues. Introdução pragmática ao Direito: de volta à gnoseologia e à semiótica do Poder. [S.I.: s. n.] (c)

RODRIGUES, Hugo Thamir; FREITAS, Daniel Dottes de.Cooperativismo Interinstitucional Público: uma proposta de gestão pública tributária para superação da guerra fiscal, em busca do desenvolvimento.In: REIS, Jorge Renato; LEAL, Rogério Gesta (org.). Direitos sociais e políticas públicas: desafios contemporâneos. Santa Cruz do Sul: EDUNISC, 2009.

YIN, Robert K. Estudo de Caso, Planejamento e Métodos. Tradução de GRASSI, Daniel. São Paulo: Bookmann, 2005.

Recebido/Received: 15.05.2020.

Aprovado/Approved: 26.07.2020. 